\title{
A REALIDADE DOS PROFESSORES DE EDUCAÇÃO FÍSICA NO ENSINO FUNDAMENTAL I E II, EM UMA ESCOLA PÚBLICA DA SEDE DO MUNICÍPIO DE MASSAPE - CE
}

\author{
LA REALIDAD DE LOS PROFESORES DE EDUCACIÓN FÍSICA EN LA \\ ESCUELA PRIMARIA I Y II, EN UNA ESCUELA PÚBLICA DE LA SEDE DEL \\ MUNICIPIO DE MASSAPE - CE
}

THE REALITY OF PHYSICAL EDUCATION TEACHERS IN ELEMENTARY SCHOOL I AND II, IN A PUBLIC SCHOOL OF THE HEADQUARTERS OF THE MUNICIPALITY OF MASSAPE $-C E$

\author{
Francisco Claudeci Faustino TEIXEIRA ${ }^{1}$ \\ Stela Lopes SOARES ${ }^{2}$ \\ Heraldo Simões FERREIRA ${ }^{3}$
}

RESUMO: Este artigo visa divulgar a realidade da prática docente na visão de professores de educação física em uma escola primária em Massapê-CE. Para isso, realizou-se um levantamento exploratório com uma abordagem qualitativa, utilizando a entrevista semiestruturada como um instrumento para a coleta de dados, com relatos de quatro professores, sobre as dificuldades recorrentes da profissão, na análise das entrevistas obtidas procurou-se interpretar os argumentos dos professores de acordo com o tema de cada questionamento. Os resultados indicaram que as dificuldades em sua realidade são: estruturas físicas inadequadas, falta de material didático-pedagógico, falta de motivação dos alunos para participarem de aulas práticas, falta de reconhecimento do verdadeiro significado do motivo físico. A educação é inserida dentro da escola, salários baixos, déficit de incentivo do governo. Este estudo, comparado a outros realizados nessa área, mostrou algum progresso na educação física, já que os professores de educação física anteriormente não participavam das reuniões com pais e cuidadores, eles não faziam parte da construção do Projeto político pedagógico. Neste estudo, foi evidenciado claramente que essa não participação de eventos escolares não existe mais na educação física da escola, fazendo o professor da área, o protagonista da ação

PALAVRAS-CHAVE: Realidade do professor. Educação física escolar. Dificuldades. Estudantes.

${ }^{1}$ Universidade Estadual Vale do Acaraú (UVA), Sobral - CE - Brasil. Graduando no Curso de Educação Física da Universidade Estadual Vale do Acaraú (UVA) e Bolsista do Programa Institucional de Bolsas de Iniciação a Docência - PIBID/UVA 2013 - Subprojeto Educação Física. ORCID: <http://orcid.org/0000-0003-3749-2603 >. E-mail: claudecyr10@ gmail.com.

2 Centro Universitário (UNINTA), Sobral - CE - Brasil. Profa. Me. no Curso de Educação Física. ORCID: <http://orcid.org/0000-0002-5792-4429>.E-mail: stelalopesoares@ hotmail.com.

${ }^{3}$ Universidade Estadual do Ceara (UECE), Fortaleza - CE - Brasil. Prof. Dr. Professor Adjunto do curso de Educação Física. ORCID: <http://orcid.org/0000-0003-1999-7982>. E-mail: heraldo.simoes@uece.br

RPGE- Revista on line de Política e Gestão Educacional, Araraquara, v. 22, n. 2, p. 572-587, maio/ago., 2018. ISSN: 1519-9029. DOI: 10.22633/rpge.v22.n2.maio/ago.2018.10543 
RESUMEN: Este artículo pretende dar a conocer la realidad de la práctica docente en la opinión de los docentes de educación física en una escuela primaria de Massapê-CE. Para ello, se realizó una encuesta exploratoria con un enfoque cualitativo, utilizando la entrevista semiestructurada como un instrumento para la recolección de datos, con informes de cuatro docentes, sobre las dificultades recurrentes de la profesión, en el análisis de la las entrevistas obtenidas interpretan los argumentos de los profesores según el tema de cada interrogatorio. Los resultados indicaron que las dificultades en su realidad son: estructuras físicas inadecuadas, falta de material didáctico pedagógico, falta de motivación de los estudiantes para participar en clases prácticas, falta de reconocimiento del verdadero significado de por qué física La educación se inserta dentro de la escuela, salarios bajos, déficit del incentivo del gobierno. Este estudio, comparado con otros realizados en esta área, mostró cierto progreso en la educación física, ya que previamente los profesores de educación física no participaron en las reuniones con los padres y los cuidadores, y no formaron parte de la construcción del Proyecto político pedagógico. En este estudio se evidenció claramente que esta no participación de los eventos escolares ya no existe en la educación física, haciendo que el profesor de dicha área, protagonista de la acción

PALABRAS CLAVE: Realidad docente. Educación física escolar. Dificultades. Estudiantes.

ABSTRACT: This article aims to publicize the reality of teaching practice in the view of Physical Education Teachers in a primary school in Massapê-CE. For that, an exploratory survey was carried out with a qualitative approach, using the semistructured interview as an instrument for the data collection, with reports of four teachers, on the recurring difficulties of the profession, in the analysis of the interviews obtained interpret the arguments of the teachers according to the theme of each questioning. The results indicated that the difficulties in their reality are: inadequate physical structures, lack of pedagogical didactic material, lack of motivation of students to participate in practical classes, lack of recognition of the true meaning of why Physical Education is inserted within the school, low wages, government incentive deficit. This study, compared to others carried out in this area, showed some progress in Physical Education, since previously Physical Education teachers did not participate in the meetings with parents and caregivers, and they were not part of the construction of the Pedagogical Political Project. In this study it was clearly evidenced that this non participation of school events no longer exists in Physical School Education, making the teacher of said area, protagonist of the action

KEYWORDS: Teacher Reality. School physical education. Difficulties. Students.

\section{Introdução}

$\mathrm{O}$ ato de educar requer um comprometimento intensivo dos componentes educacionais e de muitos outros atores também para ultrapassar os desafios e conflitos existentes nessa área do conhecimento, formadora de novos cidadãos civilizados 
capazes de conviver em sociedade harmoniosamente, pois, a todo o momento, é importante a busca por novas técnicas e métodos para atender as necessidades de uma sociedade em evolução.

Dessa forma, a Educação Física Escolar é parte do currículo escolar atuante na formação do educando que sofre com diversos problemas sociais, em que encontramos muitos professores insatisfeitos com sua prática profissional (CAMPOS et al., 2015).

Desse modo, é necessário que todos entendam sobre sua relevância, buscando o desenvolvimento das pessoas de forma independente, interativa e intelectual (SOUSA; DANIEL, 2010).

Com esse fim, os Parâmetros Curriculares Nacionais (MEC/SEF, 1997) afirmam a necessidade de estabelecer uma proposta na qual a Educação Física seja integrada às demais disciplinas, buscando alcançar os objetivos educacionais com base nos conhecimentos que lhes são próprios.

Assim, têm-se como perguntas norteadoras deste estudo científico: Como é apresentado o cenário da Educação Física na situada escola pública? Como está a Educação Física no contexto escolar atualmente? Quais os problemas enfrentados pelo docente de Educação Física escolar?

Para responder as perguntas supracitadas, faz-se necessário que o Professor de Educação Física busque um papel eficiente durante suas aulas para que sejam desconstruídos esses paradigmas criados, de que a Educação Física Escolar é aplicada de forma esportiva, competitiva, seletiva, dentre outros paradigmas que descaracterizam o verdadeiro papel da Educação Física no interior das instituições de ensino.

E sim, assumam que o docente deve trabalhar essa área do conhecimento de maneira que os discentes entendam o valor de suas aulas em seu processo formativo, utilizando-se de ferramentas pedagógicas como os conceitos, ideias, fatos, processos, princípios, leis científicas, regras, habilidades cognitivas, modos de atividade, métodos de compreensão e aplicação, hábitos de estudos, de trabalho, de lazer, de valores educativos, e em todos os âmbitos de convivência social (DARIDO, 2005).

Seguindo esta perspectiva, entende-se que o docente de Educação Física tem a função de ser um supervisor no processo de ensino-aprendizagem, beneficiando-se de seus conhecimentos para adquirir uma metodologia eficiente, almejando englobar a todos com seus conteúdos ministrados, propiciando assim, a formação do educando (SOUSA; DANIEL, 2010). 
Então, diante disso, após uma vivência acadêmica de estágio no Curso de Educação Física da Universidade Estadual Vale do Acaraú - UVA, na disciplina de Estágio Supervisionado II que acontece no Ensino Fundamental I e II, se perceberam as dificuldades enfrentadas pelos professores da referida área, assim como, a motivação para mudança de cenário, sentiu-se a necessidade de pesquisar sobre o assunto para que buscássemos as potencialidades a partir das dificuldades enfrentadas e assim, possivelmente, fomentarmos a prática docente.

Neste sentido, a relevância desta pesquisa científica está na necessidade de se discutir e sanar as dificuldades existentes no exercício da prática docente durante as aulas de Educação Física, almejando a construção de uma Educação Física idealizada com espaços físicos adequados, materiais didático-pedagógicos disponíveis para a realização de boas aulas dentro do âmbito escolar e intensificar as contribuições dessa disciplina no processo de ensino-aprendizagem dos educandos.

Esta pesquisa tem por objetivo conhecer a realidade do cotidiano de professores de Educação Física em uma escola pública, destacando as dificuldades na prática pedagógica, compreender o contexto da Educação Física no convívio escolar público no município de Massapê-CE.

\section{Revisão de Literatura}

\section{Educação Física Escolar X Dificuldades Existentes}

A Educação Física Brasileira vive uma continua evolução desde o início dos anos 80 , onde vem sendo objeto de discussão das suas tendências como um instrumento atuante na sociedade (JUNIOR, 1994, p. 15).

Ferreira e Sampaio (2013) retratam as cinco tendências que a Educação Física passou no Brasil: Higienista (que se estendeu até 1930); Militarista (1930-1945); Pedagogicista (1945-1964); Competitivista (1964-1985); e Popular (1985-atualidade).

Entender os momentos pelos quais a Educação Física passou, serve para refletirmos que a Educação Física Escolar faz parte do currículo educacional com uma ideologia hegemônica, até o momento, no âmbito escolar como disciplina constituinte no processo de ensino aprendizagem e formação dos educandos. Em seu surgimento foi influenciada por concepções pragmáticas das entidades militares, que aplicavam a 
Educação Física para proporcionar a eugenização das raças, hábitos de higiene, o patriotismo (MEDEIROS, 2009).

A inclusão da Educação Física Escolar como componente curricular obrigatório se oficializou na década de 1990, com a promulgação da Lei de Diretrizes e Bases da Educação Nacional (LDB Lei 9.394/1996) que buscou garantir seu reconhecimento na educação, assumindo uma ferramenta formativa e informativa no processo educacional. Este mesmo documento ainda propõe uma Educação Física integrada à proposta pedagógica da escola, adequando-se as diversas faixas etárias e condições do educando.

Os Parâmetros Curriculares Nacionais (PCNs) idealizam os principais objetivos da Educação Física no Ensino Fundamental: estabelecer relações sociais sem qualquer discriminação; adotando atitudes de respeito, solidariedade e cooperação; valorização da pluralidade de manifestações culturais; proporcionando hábitos de higiene e alimentação (BRASIL, 1998).

Ferreira e Sampaio (2013), afirmam que na Educação Física Escolar sempre surgem novas tendências pedagógicas ampliando seu papel no âmbito institucional, assumindo assim, outras ideologias, como: preocupação com estética corporal, higiene, construção de valores, prevenção de doenças, alimentação saudável, promoção de saúde, transversalidade, dentre outras tendências que surgirão.

Dentro do contexto da Educação Física Escolar, tem-se a necessidade de se discutir as dificuldades existentes no ensino público, dentre elas, a estrutura que as instituições de ensino disponibilizam para as aulas de Educação Física, tanto as estruturas físicas, quanto os recursos didático-pedagógicos a serem ofertados no âmbito de exercício docente, estão inclusos nessa mesma demanda.

Oliveira (2011), diz que as estruturas físicas e materiais didático-pedagógicos adequados, são de extrema importância não somente para a Educação Física.

A baixa remuneração dos professores de Educação Física é um importante fator que acaba por desmotivar os docentes, levando-os muitas vezes, a lecionarem em três instituições diferentes, ampliando assim, a carga horária do trabalho, o que de certa maneira, subtrai o tempo de engajamento no planejamento semanal, nas reuniões escolares, na elaboração do projeto político-pedagógico e nas demais atividades que se efetivam na escola. Sobre esse quadro, ressalta-se que a valorização social e real de uma área profissional se reflete nas estruturas de carreira e nos salários, considerando fatores que provocam insatisfação dos docentes diante de muitas dificuldades vivenciadas na escola (MACHADO et al, 2010).

RPGE- Revista on line de Política e Gestão Educacional, Araraquara, v. 22, n. 2, p. 572-587, maio/ago., 2018. ISSN: 1519-9029. 
Em meio aos desafios existentes dentro da Educação Física Escolar, os profissionais desta área do conhecimento, almejam exercer a profissão com métodos e técnicas pedagógicas idealizadas.

Oliveira; Sartori e Laurindo (2014, p. 19), ressaltam que a disciplina de Educação Física Escolar tem uma necessidade de ser efetivada de forma mais atrativa, alegre e agradável pelos alunos, com aulas realizadas em ambientes abertos e cobertos, e com a utilização de diferentes materiais, possibilitando um contato mais direto com o professor e colegas, permitindo assim, a utilização do próprio corpo para a aprendizagem global por meio de atividades e exercícios respeitando a sua individualidade biológica.

No entanto, para que a Educação Física efetive esse patamar de forma permanente, são necessários incentivos e subsídios por parte dos nossos idealizadores políticos com intuito de fomentar essas práticas, valorizando cada vez mais, a profissão no âmbito escolar, ultrapassando quaisquer barreiras impostas (BARROS; SCARAUSI, 2014).

As ações pedagógicas da Educação Física Escolar sendo percebidas pela sociedade como práticas significativas, motivadoras de valores, encontrando-se reconhecidas por constituir uma ferramenta primordial no âmbito dos outros meios educacionais (FIGUEIRA; PEREIRA e SOARES, 2015).

\section{Metodologia da Pesquisa}

Esta pesquisa se caracteriza como exploratória, de levantamento, com uma abordagem qualitativa, na qual utilizou-se uma entrevista semiestruturada, realizada com quatro professores de Educação Física escolar, que atuam no ensino fundamental I e II em uma escola da rede pública da sede de Massapê-CE.

Os critérios de inclusão utilizados para coleta de dados como os professores de Educação Física foram: ser professor de Educação Física na escola E.E.F. Professora Maria do Carmo Carneiro, e sentir-se motivados a participar desta pesquisa, os quatros professores da instituição de ensino concordaram fazer parte deste estudo.

A escola E.E.F. Professora Maria do Carmo Carneiro fica localizada, Rua Amadeu Albuquerque, Luiz da Hora Pereira - Centro de Massapê-CE,

Para Zikmund (2000), a pesquisa exploratória é utilizada para diagnosticar acontecimentos, explorar alternativas ou descobrir novos conhecimentos. Esse método é 
direcionado no período de estágio inicial de um processo de pesquisa mais amplo, em que se procura esclarecer e definir a natureza de um problema e gerar mais informações que possam ser adquiridas para a realização de futuras pesquisas conclusivas.

Na realização da entrevista semiestruturada com os professores de Educação Física Escolar, pretendeu-se levantar informações sobre o cotidiano de seu trabalho e a realidade da prática pedagógica dos mesmos, no ensino fundamental I e II, em uma escola da rede pública de ensino. A referida entrevista continha cinco perguntas abertas e direcionadas para o dia-a-dia do docente de Educação Física no âmbito da profissão.

A aplicação da entrevista seguiu o mesmo padrão metodológico para todos os professores engajados. Os docentes marcaram dia e horário para a entrevista, esta era realizada na sala dos professores da escola, por meio de um gravador de voz, para que a transcrição ocorresse da forma mais fidedigna possível. As entrevistas ocorreram nos turnos da manhã e tarde, com a presença do participante e do entrevistador e duraram em média 20 minutos.

Dessa forma, todos os participantes do estudo concordaram em fazer parte deste estudo através da assinatura do Termo de Consentimento Livre e Esclarecido (TCLE).

O presente trabalho atendeu todos os fundamentos éticos e científicos, da Resolução 466/12, do Conselho Nacional de Saúde de 12/12/2012, pertinentes às pesquisas envolvendo seres humanos, oferecendo riscos mínimos aos envolvidos, haja visto que todos os procedimentos éticos legais foram respeitados.

Em respeito aos princípios éticos da pesquisa, esta foi submetida e aprovada no Comitê de Ética em Pesquisa da Universidade Estadual Vale do Acaraú - UVA, localizado na Av. Comandante Maurocélio Rocha Pontes, S/N, Derby Clube, Sobral CE sob o número de CAAE 51347815.4.0000.5053.

\section{Resultados e Discussões}

Com intuito de fomentar os dados deste estudo, a seguir, iremos apresentar os principais resultados e discussões obtidos na coleta de dados, estruturados dentro da perspectiva real de cada professor de Educação Física entrevistado. Dessa forma, apresentaremos os principais pontos das entrevistas:

A primeira pergunta foi referente: "A formação inicial, assim como, sobre o cotidiano escolar e suas dificuldades na prática pedagógica”. 
Todos os professores afirmaram que as dificuldades: falta de espaço físico adequado, materiais didático-pedagógicos disponíveis, desmotivação por parte dos professores e alunos foram tratadas durante a graduação, mas em apenas algumas disciplinas como Didática, Políticas Públicas, Interação Ensino-Serviço e ComunidadeIESC, I, II, III, IV, V, e Estágios Supervisionados, ainda assim foi discutido sobre esse assunto de forma muito limitada.

Os achados desta questão evidenciam que os cursos superiores de formação inicial estão debatendo sobre os assuntos do campo de atuação dos futuros docentes, mas ainda não efetivam um convívio e uma preparação profissional concreta. É essencial que os acadêmicos em formação tenham contato direto com todos os problemas, visando como tema recorrente que vão enfrentar no cotidiano de professor.

Para Maia et al. (2012), as instituições de ensino superior devem compromete-se com a qualidade do ensino, pois elas têm a obrigação de ofertar aos futuros professores uma qualificação mais eficaz com as demandas contemporâneas, através delas surgirão novas propostas pedagógicas que auxiliarão no progresso educacional.

No período de formação profissional o docente tem como finalidade central, capacitar-se para atuar nas mais diversificadas situações, adequando-se ao ambiente de trabalho, diretrizes institucionais e a cultura social (OLIVEIRA, 2011).

Mileo e Kogut (2009) explanam que o graduando em Educação Física não deve se sustentar apenas nas vivências das disciplinas ofertadas durante o período de formação, se tem a necessidade de uma busca permanente por conhecimentos atualizados que contemplem o seu aperfeiçoamento docente de maneira especial, e quando estiver formado deve ter como meta manter-se qualificado para que possa atender as necessidades de seus educandos bem como da sociedade. Uma vez que, o mercado de trabalho busca o docente melhor qualificado, flexível e disposto para enfrentar os desafios a ele proposto, almejando uma melhoria na educação e no ensino. Portanto, apenas a formação inicial não é suficiente para a garantia da qualificação dos professores na atualidade.

Tendo a necessidade em se buscar ferramentas de iniciação a docência além das atividades ementarias das disciplinas do curso, o Programa Institucional de Bolsa de Iniciação à Docência - PIBID/CAPES se apresenta como um instrumento estimulador dos universitários em licenciatura, este programa conduz os futuros professores a conhecerem seu ambiente de atuação antes da graduação completa, proporcionando 
formações virtuais presencias, estimulando a pesquisa e escrita científica sobre os temas importantes para complementar experiências vividas na escola (SOCZEK, 2011).

Em se tratando do segundo questionamento levantado: "Os problemas da Educação Física semelhante com os das demais disciplinas e quais têm ocorrência específica na Educação Física”.

Todos os professores declararam que na educação, por completa, existem problemas, ou seja, todas as demais disciplinas da matriz curricular se defrontam com dificuldades, e os problemas que predominam apenas na Educação Física é a falta de espaços físicos adequados, a falta de materiais didáticos e a falta de participação efetiva dos alunos nas aulas práticas.

No discurso do professor F3, ele salienta o contexto educacional de modo geral, como um sistema que encara problemas. Uma participação mais presente dos pais na vida estudantil dos alunos seria, talvez, uma das possibilidades para tentar sanar alguns problemas. A solução de qualquer problema se inicia pelo o diálogo, quando esse diálogo começa entre alunos, pais ou responsáveis e os gestores escolares, aumentam as chances de serem resolvidos.

Barros e Pessoa (2015), ressaltam as contribuições que a presença dos pais nas atividades escolares podendo conscientizar seus filhos para que os mesmos honrem seus compromissos dentro da instituição de ensino e busquem excelentes resultados.

A falta de disciplina dos alunos é uma questão que preocupa bastante o âmbito educacional. Os acontecimentos revelam que os educandos estão perdendo cada vez mais, o interesse pelas disciplinas e pelo conhecimento em si, da forma como são ministradas, ou seja, de maneira acabada e com as aulas exclusivamente expositivas (GASPARI et al, 2006).

Magalhães e Arantes (2009), afirmam que é papel do docente de Educação Física, trabalhar por meio dos conteúdos da sua área do conhecimento a formação cidadã dos educandos de maneira consciente, essa formação humana engloba vivência dos valores, virtudes, princípios morais, normas, maneiras de pensar e padrões de comportamentos para viverem em sociedade como pessoas civilizadas, o professor pode facilitar a formação do aluno sem deixar de lado os aspectos afetivos e a interação professor-aluno. O bom professor conhece seus alunos e direciona as metodologias e técnicas de ensino para as necessidades dos educandos, incluindo a realidade dos alunos ao conteúdo e incentiva a sua participação e interação, fazendo assim, que reflitam sobre sua prática educativa. 
Esta pergunta se refere aos principais obstáculos enfrentados na prática docente pelos professores de Educação Física na referida escola pública.

Sobre o terceiro questionamento: "Os principais obstáculos enfrentados pelos os professores de Educação Física para ministrar boas aulas; as iniciativas tomadas para vencer os obstáculos e exemplos".

Todos os professores mencionaram a falta de materiais pedagógicos, espaços físicos adequados (a quadra que não é coberta e ainda não tem marcações oficiais), como os principais obstáculos a serem enfrentados. Quando indagados sobre as iniciativas tomadas, os professores entrevistados apresentaram metodologias ativas e diferenciadas, para tentar vencer os desafios da profissão.

Os resultados da questão supracitada, de acordo com o F3, apontam para a falta de materiais pedagógicos e as péssimas condições da quadra da escola com os principais obstáculos para os docentes de Educação Física. E, às vezes, o próprio profissional tem que tirar do seu próprio salário, que já é pouco, para comprar materiais para as aulas de Educação Física, é uma situação muito desanimadora.

O professor de Educação Física que está preparado para superar as dificuldades existentes na sua prática docente, é um agente que contribuirá para chamar a atenção da comunidade escolar, tentando provocar assim, um sentimento de solidariedade da escola para superar tais desafios, que e às vezes torna-se elemento crucial no desenvolvimento educacional (SOMARIVA; VASCONCELOS; JESUS, 2013).

É essencial considerar a infraestrutura escolar como um dos desafios que influenciam no excelente desempenho dos docentes, bem como na formação dos educandos e também, na atenção maior ao planejamento dos espaços para a prática das atividades físicas (FIGUEIRA; PERREIRA; SOARES, 2015).

Campos; Cunha e Figueiredo (2013), e Somariva; Vasconcelos e Jesus (2013), enfatizam que o professor de Educação Física acaba enfrentando diversas dificuldades no processo de ensino-aprendizagem de seus educandos, principalmente em escolas públicas. Dificuldades estas, que acabam levando o docente a desistir da profissão.

Não se deve mais aceitar esse discurso de que a referida instituição de ensino do município de Massapê-CE, não disponibiliza condições pedagógicas favoráveis para realização de excelentes aulas de Educação Física. Existe o Plano de Ações Articuladas (PAR), idealizado pelo Plano de Desenvolvimento da Educação (PDE), apresentado pelo Ministério da Educação em 2007, que coloca à disposição dos estados, dos municípios e do Distrito Federal, instrumentos eficazes de avaliação e implementação 
de políticas de melhoria da qualidade da educação, sobretudo na educação básica (MEC, 2007). Isso quer dizer que a verba destinada para melhorias na escola é distribuída ao município, mas infelizmente o dinheiro não é aplicado como realmente deveria ser aplicado na educação básica.

Esta pergunta se refere às iniciativas tomadas pelos professores de Educação Física para vencerem os obstáculos da sua prática docente na referida escola pública.

É importante que a Educação Física, como componente curricular obrigatório, seja organizada e desenvolvida de forma apropriada na escola, tendo por objetivo a formação crítica e reflexiva dos educandos, contribuindo para a legitimidade da área (JARDIM et al, 2014).

Para que a Educação Física desempenhe o seu papel primordial na formação dos educandos é necessário que as instituições de ensino coloquem à disposição dos docentes, responsáveis pela a disciplina, meios adequados, favorecendo assim o facilitador no desempenho e cumprimento do seu papel de formador no processo de ensino-aprendizagem dos educandos.

Podemos observar o quanto os recursos materiais de ensino aprendizado implementados nas escolas são ferramentas importantes dentro da prática pedagógica construída e executada pelo professor. Entretanto, podemos perceber que, muitas instituições escolares possuem recursos materiais precários e utilizados de forma “adaptável” pelo corpo docente (MORELLI; PERREIRA, 2014).

É evidente como cada professor de Educação Física cria metodologias diversificadas para tentar vencer os obstáculos existentes na profissão. Essas iniciativas visam a participação efetiva da educação Física Escolar na formação dos educandos, mesmo diante de tantas dificuldades.

Outro questionamento realizado: “A participação do professor de Educação Física nas reuniões que acontecem na escola com os pais e responsáveis dos alunos; as contribuições que a Educação Física pode oferecer participando deste evento importante na escola e a participação na construção do Projeto Político Pedagógico da escola”.

Dois professores afirmaram que participam das reuniões com pais e responsáveis, e os outros dois professores falaram que ainda não participaram destas ações porque são recém-chegados na escola e não haviam acontecido reuniões ainda.

Os resultados desta questão apontam para as contribuições que o professor de Educação Física pode desempenhar participando das reuniões de pais e responsáveis. 
Outra conquista importante foi a participação deste docente na construção de novas tendências metodológicas dentro do Projeto Político Pedagógico.

Medeiros (2009), ressalta a importância de se contemplar a Educação Física na construção do Projeto Político Pedagógico, afinal, é pensando nas aulas, bibliotecas, laboratórios, entre outros, e os espaços adequados e materiais didático-pedagógicos indispensáveis para o desenvolvimento da Educação Física Escolar.

O professor de Educação Física participando desses dois eventos: da construção do Projeto Político Pedagógico e das reuniões de pais e responsáveis, pode em um momento, construir as concepções no Projeto Político Pedagógico e em outro, efetivar as implementações delas, com iniciativas, buscando dialogar com os pais, responsáveis, alunos e demais gestores escolares durante as reuniões, tal iniciativa deverá ser realizada com o intuito de expandir a Educação Física como uma disciplina que tem sua participação eficaz e é colaboradora no processo de formação dos educandos.

Mais um questionamento direcionado: "Nas reuniões de planejamento com os professores das outras disciplinas e os gestores escolares, qual a maneira que eles se comportam diante das propostas da Educação Física".

Dois professores consultados, afirmaram que os demais educadores já conseguem entender a importância da Educação Física na escola, e os outros dois professores falaram que ainda não participaram destas ações porque são recémchegados na escola.

Nessa fala do Professor F1, percebemos os avanços que a Educação Física vem desempenhando no seu processo de legitimação dentro do espaço escolar. Tendo suas propostas discutidas juntamente com as demais áreas do conhecimento, nas reuniões de planejamento, e ainda tendo a interdisciplinaridade como uma conquista essencial.

A função da Educação Física no processo de ensino-aprendizagem dos educandos é contribuir no desenvolvimento da personalidade do aluno como um ser social, auxiliar para as conquistas de novas habilidades, fazê-lo entender as suas potencialidades físicas, para isto o docente capacitado precisa estar preparado teoricamente e ciente da grande responsabilidade que carrega durante toda sua trajetória acadêmica e reverberando na profissional (BAIÃO, 2009).

A interdisciplinaridade acontece juntamente com as demais áreas do conhecimento, as quais poderão proporcionar aos professores e aos alunos uma inclusão mais crítica no convívio social e educacional, bem como a ampliação das vivências de 
diálogos entre a diversidade de saberes e produções sociais (AZEVEDO; AMAZONAS, 2014).

\section{Considerações finais}

Este estudo evidenciou o quanto os professores de Educação Física Escolar enfrentam de dificuldades no ensino fundamental I e II da rede pública.

A pesquisa evidenciou também, alguns progressos da Educação Física Escolar, no cenário apresentado, comparados a outros estudos desenvolvidos com está mesma temática, pois professores de Educação Física que não participavam das reuniões com pais e responsáveis, ainda na construção do Projeto Pedagógico do Curso.

Os docentes de Educação Física participando dos eventos evidenciados por este estudo, que foram mencionados acima, estarão participando de forma efetiva na construção e oferta do ensino-aprendizagem de qualidade para os educandos, e com isso também contribuirão para o reconhecimento de uma área do conhecimento relevante dentro do âmbito escolar, que integra a formação do aluno, e seus resultados sejam percebidos pela sociedade de modo geral.

Mesmo a realidade do professor de Educação Física não sendo uma profissão fácil de se exercer devido a falta de uma gestão que oferte: espaços físicos adequados, materiais didáticos disponíveis para a realização de excelentes aulas de Educação Física, e também uma remuneração significativa para classe. Diante de tantos desafios na sua práxis pedagógica, o docente desta disciplina consegue buscar mecanismos para se desvencilhar e cumprir seu papel como componente curricular escolar.

A partir dos achados, consideramos que atingimos os objetivos do nosso trabalho, pois, neste estudo foram perceptíveis os avanços da Educação Física Escolar e que as grandes conquistas continuem com as novas tendências da área educacional. No êxito com resultados favoráveis, tem-se a necessidade pela busca de uma profissão idealizada.

Por fim, destaca-se que o processo educacional é contínuo e que se fazem necessárias outras investigações para que assim possamos construir a Educação Física que almejamos. 


\section{REFERÊNCIAS}

AZEVEDO, R. S.; AMAZONAS, G. A. Reflexões da Contribuição Do Pibid/Ufam para Formação Docente numa Perspectiva Interdisciplinar. 30 de julho a 01 de agosto de 2014 - Santa Maria/RS - Brasil Associação Internacional de Pesquisa na Graduação em Pedagogia (AINPGP).

BAIÃO, M. A. A Educação Física na Educação Infantil e Ensino Fundamental I. 2009. 10.f Trabalho de Conclusão de Curso (graduação em Educação Física Licenciatura) - Curso de Educação Física, Centro Universitário Metodista de Minas Izabela Hendrix, Belo Horizonte, 2009.

BARROS, A. P.; PESSOA, E. B. Reflexões Sobre a Escola. Anais do II Congresso Nacional de Educação - CONEDU, Campina Grande-PB, 2015. Disponível em:<http://www.editorarealize.com.br/revistas/conedu/trabalhos/TRABALHO_EV045_ MD1_SA17_ID3082_06082015212013.pdf>. Acesso em: 20 mar. de 2017.

BARROS, S. M. S.; SCARAUSI, V. G. A. A Psicomotricidade como Fator de Influência na Prontidão para a Aprendizagem na Escola. Famespuplouds, São Paulo, 2014.

BRASIL. Parâmetros Curriculares Nacionais: Ciências Naturais. Secretaria de Educação Fundamental. Brasília: MEC / SEF, 1998.

BRASIL. Parâmetros Curriculares Nacionais: Educação Física. Secretaria de Educação Fundamental; Brasília: MEC/SEF, 1997.

CAMPOS, G. W. S.; CUNHA, G. T. FIGUEIREDO, M. D. Práxis e Formação Paideia: apoio e cogestão em saúde. São Paulo: Hucitec, 2013.

CAMPOS, D. F. et al. As Dificuldades Encontradas pelos os Professores de Educação Física no Ensino Fundamental na Escola Pública. EFDesportes.com, Buenos Aires, año19, n. 201, Febrero de 2015.

CONSELHO NACIONAL DE SAÚDE (Brasil). Resolução No 466, DE 12 de Dezembro de 2012. Disponível em:

<http://conselho.saude.gov.br/resolucoes/2012/Reso466.pdf>. Acesso em: 02 abr. 2017.

DARIDO, S. C. Os Conteúdos da Educação Física Escolar. Rio de Janeiro:

Guanabara Koogan, 2005.

FERREIRA, H. S.; SAMPAIO, J. J. C. Tendências e abordagens pedagógicas da Educação Física escolar e suas interfaces com a saúde. EFDesportes.com, Buenos Aires, Ano 18, n. 182, julho de 2013.

FIGUEIRA, P. F.; PEREIRA, A. L. S.; SOARES, R. L. Infraestrutura Escolar: Pode Interferir nas Aulas de Educação Física? V Extremos de Sul. Educação Física e Esportes de Atuação: Interlocuções e diálogos com os discursos Escolar, da Saúde, da Recreação! Lazer e do Treinamento. Furg - Rio Grande do Sul - RS/ 14, 15, e 19 de outubro de 2015. 
GASPARI, T. C. et al. A Realidade dos Professores de Educação Física na Escola: Suas Dificuldades e Sugestões. R. Mim. Educ., Viçosa, v. 14, n. 1, p. 109-137, 2006.

JARDIM, N. F. P. et al. A Educação Física como Componente Curricular na Educação Infantil e nas Séries Iniciais do Ensino Fundamental. Pensar a Prática, Goiânia, v. 17, n. 4 , out./dez., 2014.

JUNIOR, P. G. Educação Física Progressista - A Pedagogia crítico-social dos conteúdos e a Educação Física Brasileira. $3^{\text {a }}$ ed. São Paulo: Editora Loyola, 1994.

LDB. Lei de Diretrizes e Bases da Educação Nacional. Lei 9394/96. Ed. APP Sindicato, 1997.

MACHADO, T. S. et al. As práticas de desinvestimento pedagógico na Educação Física escolar. Revista Movimento, v. 16, n. 2, p. 129-147, abr./jun., 2010.

MAGALHÃES, E.; ARANTES, A. C. A competência profissional e o professor de Educação Física. EFDesportes.com, Buenos Aires, ano 13, n. 128, enero de 2009.

MAIA, M. F. M. et al. Primeiros Socorros nas Aulas de Educação Física nas Escolas. Fontoura Editora, v, 11, n. 1, p. 195-204, 2012.

MEDEIROS, A. S. Influências dos Aspectos Físicos e Didáticos Pedagógicos nas Aulas de Educação Física em Escolas Municipais de Belém. Revista Científica da UFPA, v.7, n. 01, 2009.

MILEO, T. R.; KOGUT, M. C. A Importância da Formação Continuada do Professor de Educação Física e a Influência na Prática Pedagógica. Anais do IV Congresso Nacional de Educação - ENDUCERE, III Encontro Sul Brasileiro de Psicopedagogia. PUC-PR, 26 a 29 de outubro de 2009.

MINISTÉRIO DA EDUCAÇÃO. Plano de Ações Articuladas - PAR. Disponível em:<http://simec.mec.gov.br/cte/relatoriopublico/principal.php>. Acesso em: 22 de mar. 2017.

MORELLI, N. J.; PERREIRA, J. M. As Dificuldades Encontradas pelos Professores de Educação Física nas Escolas. IX Jornada Científica Faculdades Integradas de Bauru - FIB ISSN 2358-6044, 2014.

OLIVEIRA, R. H. Problemas e Soluções da Educação Física Escolar: um Estudo Bibliográfico. 2011. 12f. Trabalho de Conclusão de Curso (graduação em Educação Física Licenciatura), Universidade Federal do Rio Grande do Sul, Porto Alegre, 2011.

OLIVEIRA, A. R. C.; SARTORI, S. K.; LAURINDO, E. Recomendações para a Educação Física Escolar. Sistema CONFEF/CREFs Conselhos Federal e Regionais de Educação Física. 2014. Disponível em: $<$ http://www.listasconfef.org.br/arquivos/RECOMENDACOES_PARA_A_EDUCACA O_FISICA_ESCOLAR2.pdf $>$. Acesso em: 16 mar. 2017. 
SANTOS, A. H. G.; ASSIS, L. R. Psicomotricidade. In: RICCI, S. M. (Coord.). Publicação Científica do Centro Técnico-Educacional Superior do Oeste Paranaense Ctesop, N1, Assis Chateaubriand - PR, Revista Científica Multidisciplinar Unimeo, 2007, p. 94-97.

SOMARIVA, J. F. G.; VASCONCELOS, D. I. C. J.; JESUS. T. V. As dificuldades enfrentadas pelos professores de Educação Física das escolas públicas do Município de Braço do Norte. Santa Catarina, 2013.

SOCZEK, D. PIBIB como formação de professores: reflexões e considerações preliminares. Revista Brasileira de Pesquisa sobre Formação docente, Belo Horizonte, v. 3, n. 5, p. 57-69, ago./dez., 2011.

SOUSA, J. D.; DANIEL, M. M. C. Importância da Educação Física Escolar na Visão dos Alunos de uma Escola Pública. CONGRESSO NORTE-NORDESTE DE PESQUISA E INOVAÇÃO, 2010. p. 1-7.

ZIKMUND, W. G. Business research methods. 5 ed. Fort Worth, TX: Dryden, 2000.

\section{Como referenciar este artigo}

TEIXEIRA, Francisco Claudeci Faustino.; SOARES, Stela Lopes.; FERREIRA, Heraldo Simões. A realidade dos professores de educação física no ensino fundamental I e II, em uma escola pública da sede do município de Massapê - CE. Revista on line de Política e Gestão Educacional, Araraquara, v. 22, n. 2, p. 572-587, maio/ago., 2018. ISSN: 1519-9029. DOI: 10.22633/rpge.v22.n2.maio/ago.2018.10543

Submetido em: 18/10/2017

Revisões requeridas: 10/01/2018

Aprovado em: 20/04/2018 